\title{
Traumatic ulcer distribution of patiens with removable orthodontic appliance in Orthodontics Clinics of Dental Specialist Program
}

\author{
Gusti Akbari*, Tenny Setiani Dewi*, Isnaniah Malik** \\ *Department of Oral Medicine, Faculty of Dentistry Universitas Padjadjaran \\ **Department of Orthodontics, Faculty of Dentistry Universitas Padjadjaran
}

\begin{abstract}
Introduction: Treatment with fixed orthodontic appliance sometimes cause the oral mucosa lesion, known as a traumatic ulcer. The purpose of this research is to see the distribution of traumatic ulcer on the patient with a fixed orthodontic appliance in PPDGS Orthodontic RSGM FKG Unpad Clinic. Methods: This research used a descriptive observational method. The sample of this research consisted of 39 people who participate in the interview and willing to be examined the condition of their oral mucosa during the study. Results: Twenty three samples or about 59\% from all the sample have a traumatic ulcer on the oral mucosa. Conclusion: Most of the patient with a fixed orthodontic appliance has a traumatic ulcer, which mostly located on the buccal mucosa, followed by labial mucosa, and gingiva.
\end{abstract}

Keywords: fixed orthodontic appliance, oral mucosa, traumatic ulcer.

\section{INTRODUCTION}

The crowding of teeth is an essential issue for most individuals since long ago. Several tools were created to improve the teeth arrangement. Treatment in dentistry that uses a variety of tools to improve malocclusion or tooth malposition, is known as orthodontic. Orthodontic treatment also plays a role in enhancing mastication function, improving oral health, as well as improving the appearance and aesthetic of facial profile. ${ }^{1,2,3}$

Orthodontic treatment can be performed using a removable orthodontic or orthodontic appliance depending on the severity of the case. ${ }^{4}$ An orthodontic treatment that is popular nowadays is the usage fixed orthodontic appliance.
This can be seen from the number of patients who have come to do treatment using the fixed orthodontic appliance at the Clinic for dental Education specialist orthodontics of dental and oral medicine Faculty of Dentistry Padjadjaran University, Bandung.

Patients undergoing treatment using the fixed orthodontic appliance often have irritation to the oral mucosa in a period of time it fixed on the tooth. ${ }^{5} \mathrm{~A}$ research that was done by Kvam, , has stated that from 161 patients that used fixed orthodontic appliance, $95 \%$ of them admit that they have painfully experienced due to the mucosal irritation in the oral cavity after the use of the fixed orthodontic appliance. Around 84.5\% of the patient mentioned that the pain sensation 
only appears at the earlier time the usage of fixed orthodontic appliance, whereas the other $11 \%$ have experienced the pain regularly along the treatment. ${ }^{6}$

The fixed orthodontic appliance consists of wire, bracket, band, tube, hook and other supporting components inside the oral cavity, which can cause friction to the mucosa and leads to mucosal irritation. The injury caused by the use of the fixed orthodontic appliance is known as a traumatic ulcer. The traumatic ulcer usually heals by itself after the cause of irritation is gone. ${ }^{7,8,9}$ Based on the statement above, the author is attracted to do a research on to know the traumatic ulcer distribution of patient that use the fixed orthodontic appliance in the orthodontist clinic at dental school of Padjadjaran University (RSGM), Bandung, for 2002 February period. The aim of this research is to know the traumatic ulcer distribution of patient that use fixed orthodontic appliance in the orthodontist clinic at dental school of Padjadjaran University (RSGM), Bandung, for 2002 February period.

\section{METHODS}

The type of research that will be used in this research is observational descriptive. This research is conducted in a certain period of time with the aim to picture or described a phenomenon without any intervention with the research subjects. ${ }^{10}$ The population in this research are those who use fixed orthodontic appliance which also come for control at the orthodontist clinic of the dental hospital of Padjadjaran University (RSGM) during the whole February of 2012. The inclusion criteria include patient that is treated using fixed orthodontic appliance who also come for control at the orthodontist clinic of dental hospital of Padjadjaran University (RSGM) during the whole February of 2012 and who agreed to be observed throughout the research by signing the informed consent. Whereas, the exclusion criteria include the patient who have a bad systemic condition or any systemic condition where it can affect the healing of the wound such as diabetes, hemophilia, anemia, leukemia, immunodeficiency and autoimmune disease, menstruating patient or pregnant, and those who refuse to be observed and not signing the informed consent.

\section{RESULTS}

From this research which has been done for the whole of February of 2012, some samples are obtained consist of 39 patients that fulfil the inclusion criteria. Table 1 shows a picture of the patient who uses fixed orthodontic appliance in the orthodontist clinic at the dental school of Padjadjaran University (RSGM), Bandung, for 2002 February period.

Table 1 shows that the research subject based on gender, men is less compared to women. Men consist of 9 people $(23.1 \%)$ while women consist of 30 people $(76.9 \%)$ based on age, the research subject consists of the most for $16-25$ age years old, which is 33 people or around $84.6 \%$

Table 1. Research Subject Distribution based on the Gender, Age Length of Treatment.

\begin{tabular}{ccc}
\hline & N & $\%$ \\
\hline Gender Women & 30 & 76.9 \\
Men & 9 & 23.1 \\
Total & 39 & 100.0 \\
Age (Years) $16-25$ & 33 & 84.6 \\
$26-35$ & 5 & 12.8 \\
$36-45$ & 1 & 2.6 \\
Total & 39 & 100.0 \\
Length of Treatment (years) $0-0.5$ & 6 & 15.4 \\
$0.5-1$ & 8 & 20.5 \\
$1-1.5$ & 6 & 15.4 \\
$>1.5$ & 19 & 48.7 \\
\hline Total & 39 & 100.0 \\
\hline
\end{tabular}

from the whole sample while those who are $36-45$ years old are only one person or around $2.6 \%$ from the whole sample. Most of the patient has used the fixed orthodontic appliance for more than 1.5 years, which is 19 people, around $48.7 \%$ from the whole total sample. Besides that, some of the research subject that used it around 0-6 months, which consist of 8 subjects.

On Diagram 1 it can be seen that the majority user of fixed orthodontic appliance at the orthodontist clinic, Dental Hospital faculty of dentistry of Unpad, men or women have traumatic ulcer lesion at their oral mucosa. The amount of women patient who used fixed orthodontic appliance and are positive on having traumatic ulcer on their oral mucosa is more about $60 \%$ compared to men (55.6\%) Diagram 2 shows that there are $57.6 \%$ research subjects that are $16-25$ 


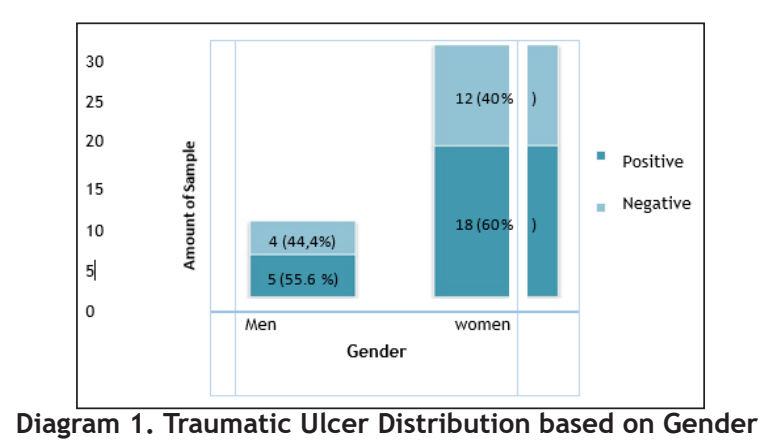

years old positively have traumatic ulcer whereas research subjects who are 26-35 years old have $60 \%$ positive with traumatic ulcer. In a range from 36-45 years old, only 1 person that are positive towards traumatic ulcers on his oral mucosa. Moreover, based on Diagram 4.3, it can be seen there is no difference between the appearances of

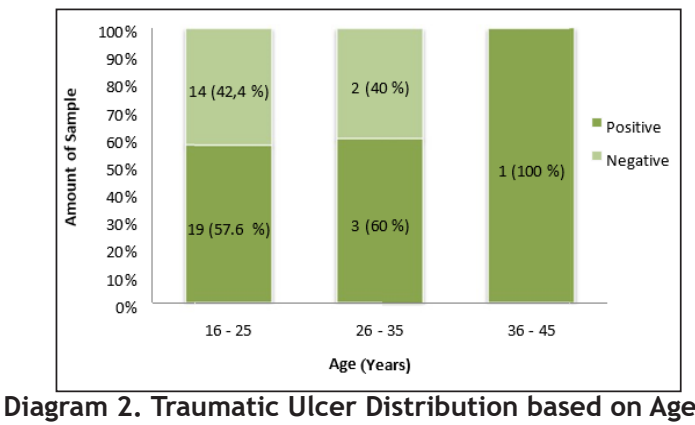

traumatic ulcer with the length of treatment. For a new patient that has just received the treatment of fixed orthodontic appliance for 0-6 months, there 3 persons that are positive with a traumatic ulcer in their oral mucosa, not so different with those who already received the treatment for 1.5 years. About 11 people or around $57 \%$, also have

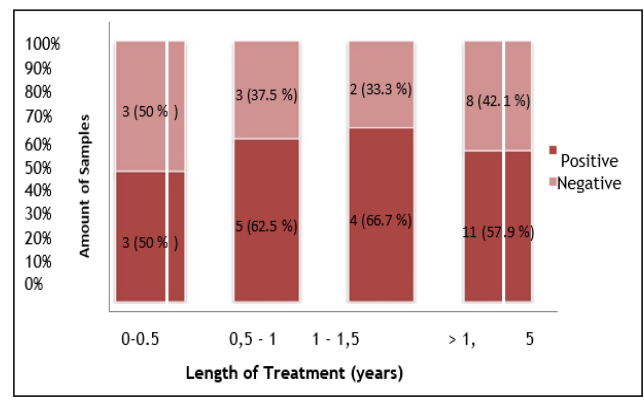

a traumatic ulcer on their oral mucosa. Diagram 4 shows the traumatic ulcer distribution based on location on research subjects. About 16 persons have a traumatic ulcer on buccal mucosa and the least one where there is one subject have a traumatic ulcer on his/her gingival mucosa Picture 1 shows a Traumatic Ulcer on the buccal mucosa of a patient that used fixed orthodontic appliance.

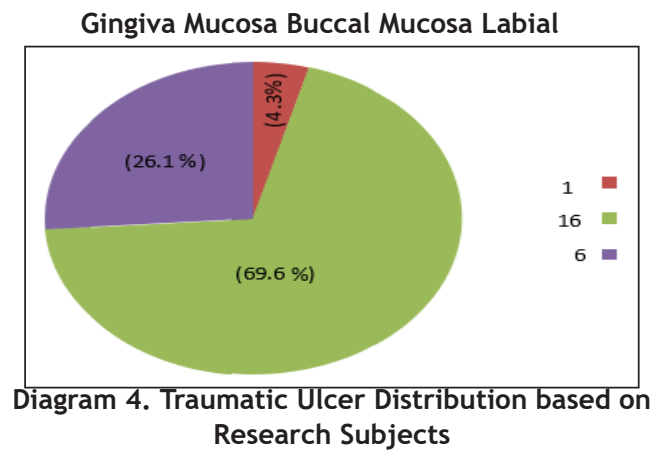

Picture 2 Shows that Traumatic Ulcer on labial mucosa of a fixed orthodontic appliance patient, accurately its exactly on region 1 canine

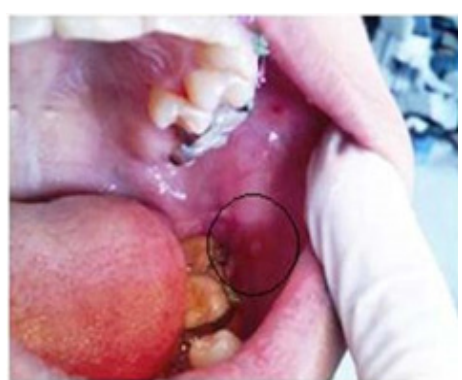

Gambar 1. Traumatic Ulcer pada Mukosa Bukal

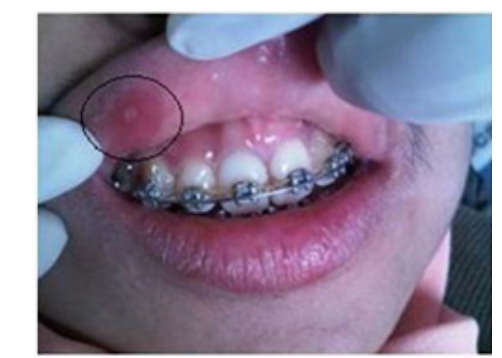

Picture 2. Traumatic Ulcer on Labial Mucosa

\section{DISCUSSION}

The result of this research shows that there are 23 from 39 samples patient of the fixed orthodontic appliance at orthodontist clinic of the dental hospital, Padjadjaran University (RSGM) in a whole month of February 2012 that fulfil the inclusion criteria, have traumatic ulcer lesion in their oral cavity. This matter shows that the prevalence of traumatic ulcer is high, which is $59 \%$, similar to research done by ${ }^{5,6}$ Asher and Shaw (1986) 
dan Kvam, et al., (1987) where has stated that most of the patients have irritation on their oral mucosa caused by fixed orthodontics appliance components.

The results in Table 1 shows that the number of women that used fixed orthodontic appliance is more than men which is 30 from the whole sample. This matter shows that women is more attracted to undergo fixed orthodontic appliance treatment compared to men. This is because the tendency to show their appearance is high compared to men. ${ }^{11}$

On Diagram 1, it can be seen that women have traumatic ulcer more than men because of the number of samples for women is more than men. According to ${ }^{12}$ women are susceptible to have an ulcer on their oral mucosa because of their tendency for having imbalance hormone as long as they live. When in menstruation, an ulcer appears on oral mucosa that connected with hormonal factor, estrogen and progesterone. This matter is supported by lots of research which proves that oral mucosa is sensitive towards steroid hormone ${ }^{13,14}$

In terms of age, the sample in this research is from teenagers and young adult. For teenagers, they usually motivated to use the fixed orthodontic appliance with support from their parents while those who are at the age of young adult mostly are not satisfied towards their appearance. ${ }^{15,16}$ Orthodontic treatment in teenage years is the most effective time because of all the teeth already erupted and the growth of maxillary and mandibular are already complete; however, it still can be modified.

Whereas, the orthodontic treatment for a young adult would need a long time because of the growth and development of bones are already finish ${ }^{1,17}$ The distribution of traumatic ulcer based on the age of the patient that is shown in Diagram 4.2 shows that each of the age group, there is no real difference with the appearance of a traumatic ulcer. This matter shows that the appearance of a traumatic ulcer does not have any relationship with age factor unless there is mechanical trauma caused by the fixed orthodontic appliance components which usually appear after pressure has been given during control with dentist. ${ }^{3}$

On diagram 3, it can be seen that traumatic ulcer distribution based on length of time of treatment where there are patients who already done the treatment for 1.5 years, and there are some patients who have just begun their treatment for 6 months, there is no difference between them. This matter shows that traumatic ulcer will be gone when the mechanical trauma caused by the components of the appliance is removed. 18,19,20 Based on Diagram 4, traumatic ulcer is mostly found on the buccal mucosa of the patients, accurately on the area where a band is placed at the molar region follows by labial mucosa and out of everyone in the sample only 1 appears to have traumatic gingival ulcers. These matters are expected because of the relationship between orthodontic components that functions as a place of attachment of band, where it is a passive component of fixed orthodontic appliance that is placed usually on supra or sub gingiva, usually cause inflammation on surrounding mucosa. ${ }^{21}$

Picture 1 shows traumatic ulcer lesion on mucosal buccal for fixed orthodontic patient appliance patient. Accurately around the orthodontic band. Most of the traumatic ulcer lesion on buccal mucosal especially at the posterior part, because it was suspected that it connected with the orthodontic component that is attached to the band, like a tube. Tube made contact with buccal mucosa until it causes an irritation which leads to a traumatic ulcer. Besides that, a tube is an end terminal from active components, which is arch wire where sometimes the wire is too long, therefore, causing the irritation on surrounding mucosa.

This matter are parallel with research that has been done, the placement of band on the posterior teeth will cause mucosal irritation around it, periodontitis and tooth decay. ${ }^{22}$ Besides that, a traumatic ulcer that often occurs in users of the fixed orthodontic appliance due to excessive muscular activity on the cheeks. Traumatic ulcer in the labial mucosa area and gingiva is found fewer than in the buccal mucosa. It is related to the placement of the component orthodontic components, which in the area of the buccal there is a band that is always in the series orthodontic and serves as a component of the anchoring, while in the labial mucosa rarely contact with Its fixed orthodontic components vary depending on the case of each patient.

Picture 2 shows that there is traumatic lesion which caused by hook components on canine 
tooth. Hook functionally as a handle from elastic rubber that connect the upper and lower jaw with the aim to close the gap and tooth rotation and also as well as in the initial stage of the teeth that stray considerably, so that this component is not necessarily used by any patients users of fixed orthodontic appliance, but depending on the type of movement needed and of course varies between patients with the patient ${ }^{4}$.

\section{CONCLUSION}

Most users of an orthodontic appliance in the clinic of dental education programs Orthodontics Specialist, Faculty of Dentistry Padjadjaran University have a traumatic ulcer, which is located at most in the buccal mucosa, followed by the labial mucosa, and gingiva.

\section{REFERENCES}

1. Proffit WR, Fields HW, Sarver DM. Contemporary Orthodontic. $4^{\text {th }}$ ed. St. Louis: Mosby Elsevier. 2007. 3, 167, 234, 635 pp.

2. Heintze SD, Brinkmann P, Finke C, Miethke R. Oral Health for the Orthodontic Patient. $1^{\text {st }}$ ed. Chicago: Quintessence. 1999. 1-10 pp.

3. Lau PYW, Wong RWK. Risk and complication in orthodontic treatment. HK Dent J. 2006;3(1):84-91.

4. Foster TD. Buku Ajar Orthodonsi. $3^{\text {rd }}$ ed. Jakarta: EGC. 1993. 162-182, 213, 240-242 pp.

5. Asher C, Shaw WC. Benzydamine hydrochloride in the treatment of ulceration associated with recently placed fixed orthodontic appliances. Eur J Orthod. 1986 Feb;8(1):61-4.

6. Kvam E, Gjerdet NR, Bondevik O. Traumatic ulcers and pains during orthodontic treatment. Community Dentistry and Oral Epidemiology. 1987;15(2):104-107.

7. Gandolfo S, Scully C, Carrozzo M. Oral Medicine $1^{\text {st }}$ ed. Edinburgh: Churchill Livingstone. 2006. $141 \mathrm{pp}$.

8. Sonis ST, Fazio RC, Fang L. Principles and Practice of Oral Medicine $2^{\text {nd }}$ ed. Philadelphia: WB Saunders Company. 1984. 22, 345-346 pp.

9. Langlais RP, Miller CS. Atlas Berwarna Kelainan Rongga Mulut yang Lazim. Jakarta: EGC. 2000. $94 \mathrm{pp}$.

10. Sastroasmoro S. Dasar-Dasar Metodologi
Penelitian Klinis. ${ }^{\text {th }}$ ed. Jakarta: Perpustakaan Nasional RI: Katalog Dalam Terbitan (KDT). 2002. 82, 98 pp.

11. Harris DL, Carr AT. Prevalence of concern about physical appearance in the general population. $\mathrm{Br}$ J Plast Surg. 2001 Apr;54(3):223-6. DOI: 10.1054/bjps.2001.3550

12. Välimaa $H$, Savolainen $S$, Soukka T, Silvoniemi P, Makela S, Kujari H, Gustafsson JA, Laine $M$. Estrogen receptor- $B$ is the predominant estrogen receptor subtype in human oral epithelium and salivary glands. J Endocrinol. 2004 Jan;180(1):55-62. DOI: 10.1677/ joe.0.1800055

13. Apoorva SM, Suchetha A. Effect of sex hormones on the periodontium. Ind J Dent Sci. 2010;2(5):36-40.

14. Wray D, Ferguson MM, Mason DK, Hutcheon AW, Dagg JH. Recurrent aphthae: treatment with vitamin B12, folic acid, and iron. $\mathrm{Br}$ Med J. 1975 May 31; 2(5969): 490-493. DOI: 10.1136/bmj.2.5969.490

15. Buttke TM, Proffit WR. Referring adult patients for orthodontic treatment. J Am Dent Assoc. 1999 Jan;130(1):73-9. DOI: 10.14219/jada. archive.1999.0031

16. Oliveira CM, Sheiham A. Orthodontic treatment and its impact on oral health-related quality of life in Brazilian adolescents. Journal of Orthodontics. 2004;31():20-27.

17. Moyers, R.E. 1988. Handbook of Orthodontics $4^{\text {th }}$ ed. Chicago: Year Book. Medical Publishers, Inc. 3, 332, 473 pp.

18. Dewi TS, Usri K, Riyanti E, Aripin D; Rusminah $\mathrm{N}$, Arwana AJ, Syiarudin I. Diagnosis dan Terapi Penyakit Gigi dan Mulut. Bandung: LSKI Yayasan Bale Cijulang. 2008. 60-61, 102 pp.

19. Field A, Longman L. Tyldesley's Oral Medicine $5^{\text {th }}$ ed. New York: Oxford. 2004. 1, 6-9, 51-52 pp.

20. Langlais RP, Miller CS. Atlas Berwarna: Kelainan Rongga Mulut yang Lazim. Jakarta: EGC. 2000. 94 pp.

21. Demling A, Heuer W, Eher C, Heidenblut T, Bach FW, Schwestka-Polly R, Scholz SM. Analysis of supra- and subgingival long-term biofilm formation on orthodontic bands. Eur J Orthod. 2009 Apr;31(2):202-6. DOI: 10.1093/ ejo/cjn090.

22. Berglundh T, Lindhe J, Ericsson I, Marinello 
CP, Liljenberg B, Thomsen P. The soft tissue barrier at implants and teeth. Clin Oral
Implants Res. 1991 Apr-Jun;2(2):81-90. DOI: 10.1034/j.1600-0501.1991.020206.x 